\title{
PEGARUH HARGA DAN PERIKLANAN MELALUI INTERNET TERHADAP KEPUTUSAN PEMBELIAN PRODUK SABUN MEREK LUX PADA MAHASISWA STIE "KBP" PADANG
}

\author{
Sri Jamarnis, Febsri Susanti \\ Sekolah Tinggi Ilmu Eknomi "KBP" \\ febsrisusanti@akbpstie.ac.id
}

\begin{abstract}
The formulation of the problem is to know how the influence of prices and advertising via the internet against the purchase decision of Lux brand soap. From the results of the research can be known responses of respondents about prices and perkilanan via the internet can be said quite well which resulted in good decisions purchase soap brand products Lux. This type of research is qualitative and quantitative.

Based on the result of $t$ test of price to purchase decision found sig or probality value for variable price $0.000<\alpha=0,05$ then decision is Ha accepted and Ho rejected, mean can be concluded that price variable have significant influence to purchasing decision on Lux brand soap product. As for the advertising variables through the internet to the purchase decision found sig or probality value for advertising variables via the internet $0,000>\alpha 0.05$ for advertising via the internet decision is Ha rejected and Ho accepted, it can be concluded that the advertising variables through intrnet have no significant influence against the purchase decision of Lux brand soap products.

In the value of $F$ test to measure the influence of price variables, and advertising through the internet simultaneously then found sig $0.000<\alpha=0,05$ then the decision is Ha accepted and Ho rejected, it means dapt concluded that each variable has a significant influence on product purchasing decisions Lux brand soap simultaneously. From Adjusted $R$ Square value is produced simultaneously 93,8\%. The decision to purchase Lux brand soap products is influenced by prices and advertising over the internet while $6.2 \%$ is influenced by other variables not examined in this study.

Keywords: Price, Advertising via Internet and Purchase Decision.
\end{abstract}




\section{PENDAHULUAN}

Perkembangan dunia saat ini berjalan dengan pesat, yang menciptakan suatu persaingan yang semakin ketat. Hal ini menuntut produsen untuk lebih peka, kritis dan kreatif terhadap perubahan yang ada, baik politik, sosial budaya dan ekonomi. Isu globalisasi dan informasi telah membawa masyarakat khususnya mahasiswa lebih kritis dan peka didalam pemilihan produk yang mereka konsumsi. Hal ini juga berpengaruh pada pola hidupnya yang mengalami pergeseran pada kondisi seperti ini, mahasiswa sebagai salah satu konsumen suatu barang akan dapat memilih produk yang sesuai dengan keinginan, kebutuhan, keuangan dan seleranya. Banyak faktor yang mempengaruhi perilaku konsumen dalam keputusan pembelian adalah hal yang penting, sebab dengan pengetahuan dasar yang baik mengenai perilaku konsumen akan dapat memberikan masukan yang berarti bagi perencanaan strategi pemasaran. Sebagai seorang pemasar harus melaksanakan kegiatan pemasaran yang sesuai dengan keinginan dan kebutuhan konsumen.

Harga merupakan salah satu variabel yang harus dikendalikan secara benar, karena harga akan sangat berpengaruh terhadap beberapa aspek kegiatan perusahaan, baik menyangkut kegiatan penjualan maupun aspek keuntungan yang ingin dicapai oleh perusahaan. Secara umum pengertian harga adalah nilai pertukaran dari suatu produk atau jasa. Ini adalah jumlah yang dibayar oleh seorang pembeli untuk suatu barang atau jasa. Hal ini dapat merupakan nilai yang diminta oleh seorang penjual untuk barang yang ditawar untuk dijual. Harga adalah faktor utama dalam bersaing untuk menjual maupun barang konsumen.

Iklan merupakan komunikasi persuasif dalam kegiatan pemasaran, dengan tujuan untuk membujuk khalayak (calon konsumen), guna untuk mengenalkan, memberitahu hingga menggunakan atau mengkonsumsi barang atau jasa yang ditawarkan oleh suatu perusahaan atau instansi. Selain itu iklan juga digunakan sebagai suatu bentuk pencitraan mengenai perusahaan tersebut melalui barang atau jasanya. Iklan online adalah mempromosikan sebuah produk di internet dengan menggunakan berbagai fitur internet, dengan kedatangan internet, dunia bisnis telah menjadi digital dan orang lebih suka membeli produk yang diiklankan di sosial media atau mealui internet. Iklan online sekarang menjadi pusat perhatian bagi para investor atau pemasang iklan, karena dengan menggunakan iklan online tidak perlu mengeluarkan biaya yang besar tetapi mendapatkan hasil yang maksimal. Karena internet mencakup seluruh dunia. Online 
advertising atau iklan online adalah metode periklanan dengan menggunakan internet dan word wide web dengan tujuan menyampaikan pesan pemasaran (promosi) untuk menarik pelanggan.

Dengan perkembangan zaman sabun mandi tidak hanya berbentuk batangan, tetapi kini telah ada yang berbentuk cair. Sabun mandi cair tidak hanya berfungsi untuk membersihkan saja, tetapi menampilkan beberapa nilai manfaat dan kegunaan, seperti melembutkan kulit, juga ada yang telah mengandung deodoran. Oleh karena itu perlu bagi pemasar untuk mengetahui faktor-faktor yang mempengaruhi proses pemilihan konsumen terhadap produk sabun mandi cair yang ada, dengan mempelajari perilaku konsumen yang dituju.

Kita sudah mengenal dengan salah satu produk sabun yang bermerek Lux. Dilihat dari gencarnya promosi iklan Lux yang di tayangkan di TV dan juga di internet menandakan produk ini masih mempunyai keunggulan yang lebih terutama dalam bidang promosi produk. Agar mudah dikenal oleh masyarakat, Lux melakukan promosi dengan menjadikan artis yang berperan dalam iklan yang ditayangkan dimedia masa, sehingga terkesan produk ini sangat bermutu, selain itu Lux juga mendesain atribut produknya dengan berbagai variasi, seperti warna, kemasan, aroma, dan atribut-atribut lain yang melekat pada produk ini, sehingga konsumen dapat memilih produk sabun Lux seperti apa yang mereka inginkan.

Gebrakan LUX lima tahun terakhir ini belum terlihat nendang. Beberapa hasil survei memperlihatkan sabun LUX seolah kalah pamor dibanding sabun kecantikan lain yang menyerbu pasar, baik sabun dari dalam maupun luar negeri. Hasil survei Indonesian Customer Satisfaction Award 2013, misalnya pangsa merek LUX di kategori sabun padat yang 13,6\%, masih kalah jauh dari pangsa merek Lifebuoy 45,9\%. Sementara dikategori sabun cair, pangsa merek LUX angkanya lebih tinggi 18,8\%. Meski demikian, posisinya masih di bawah Lifebuoy cair 37,9\%.

Ada apa dengan LUX ? Jika merunut kebelakang, persoalan yang dihadapi sabun kecantikan para bintang ini memang sangat kompleks. Pertama, aspirasi konsumen berubah. Dulu, konsep kecantikan bintang film memang impian setiap wanita Indonesia. Sekarang, dengan semakin tingginya latar pendidikan dan pendapatan mereka, kecantikan yang diimpikan yang wanita bukan hanya cantik fisik, melainkan cantik dari dalam. Wanita Indonesia makin percaya diri sehingga simbol kecantikan dari para bintang tidak menarik lagi. Kedua, makin banyak sabun mandi dari dalam dan luar negeri yang sesuai dengan personalitas wanita modern. Hal ini mempengaruhi permintaan LUX 
menjadi turun. Terlebih seperti halnya kosmetik, wanita kelas menengah enggan disamakan dengan pekerja yang di anggap strata ekonominya dibawah mereka. Ketika masyarakat menengah bawah menggunakan sabun LUX, seketika itu pula para wanita kelas menengah akan meninggalkannya. Ketiga, salah satu bintang LUX tersandung kasus video mesum. Entah tersandung atau tidak, sejak saat itu, LUX seperti meredup. Meskipun Unilever langsung mengganti Luna Maya dengan Atiqah Hasiholan sebagai duta merek LUX yang baru, tidak berhasil mengembalikan kejayaannya. Kita tahu, pemilihan bintang LUX sebelumnya selalu cantik dan terkenal, seperti Ida Iasha, Tamara Bleszynski, Febi Febiola, Desy Ratnasari, Dian Sastrowardoyo. Nah, kasus dengan Luna Maya telah mencoreng reputasi bintang selama ini.

\section{KAJIAN PUSTAKA}

\section{Pengertian Keputusan Pembelian}

Merupakan sebuah tindakan yang dilakukan konsumen untuk membeli suatu produk. Setiap produsen pasti mrnjalankan berbagai strategi agar konsumen memutuskan untuk membeli produknya. Menurut Kotler (2002), keputusan pembelian adalah tindakan dari konsumen untuk mau membeli atau tidak terhadap produk. Dari berbagai faktor yang mempengaruhi konsumen dalam melakukan pembelian suatu produk atau jasa, biasanya konsumen selalu mempertimbangkan kualitas, harga dan produk yang sudah dikenal oleh masyarakat.

\section{Pengertian Harga}

Harga merupakan salah satu variabel yang harus dikendalikan secara benar, karena harga akan sangat berpengaruh terhadap beberapa aspek kegiatan perusahaan, baik menyangkut kegiatan penjualan maupun aspek keuntungan yang ingin dicapai oleh perusahaan.

Menurut Philip Kotler, (2008), harga adalah jumlah semua nilai yang diberikan oleh semua pelanggan untuk mendapatkan keuntungan dari memiliki atau menggunakan suatu produk atau jasa.

\section{Pengertian Periklanan}

Kata iklan berasal dari bahasa yunani, iklan merupakan suatu bentuk komunikasi massa melalui berbagai media massa yang dibayar oleh perusahaan perusahaan bisnis, organisasi non profit dan individu-individu yang teridntifikasi dalam pesan periklanan dengan maksud memberi informasi atau mempengaruhi pemirsa dan golongan tertentu bentuknya dapat berupa tulisan, gambar, film, ataupun gabungan dari keseluruhan unsur tersebut. Urat nadi kehidupan televisi (swasta) terletak pada iklan. 


\section{Hipotesis}

Hipotesis menurut Sugitono (2004) adalah jawaban sementara terhadap rumusan masalah penelitian. Hipotesis harus dibuktikan kebenarannya karena masih merupakan dugaan. Hipotesis yang akan diuji adalah sebagai berikut :

$\mathrm{H}_{1}$ : Harga berpengaruh signifikan terhadap penjualan produk sabun merek LUX.

$\mathrm{H}_{2}$ : Iklan mealui internet berpengaruh signifikan terhadap penjualan produk sabun merek LUX.

\section{Jenis Penelitian}

Jenis penelitian ini bersifat kualitatif dan kuantitatif. Penelitian kualitatif memberikan gambaran respon sampel penelitian mengenai periklanan melalui internet dan pemasaran terhadap keputusan pembelian Sabun Lux. Penelitian kuantitatif data yang berbentuk angka yaitu untuk menganalisa pengaruh dari periklanan melalui internet dan pemasaran terhadap pembelian Sabun Lux.

\section{Populasi dan Sampel}

1. Populasi

Populasi merupakan wilayah
generalisasi yang terdiri atas subyek
atau objek yang memiliki karakter dan
kualitas tertentu yang ditetapkan oleh
seorang peneliti untuk dipelajari yang
kemudian ditarik kesimpulan. (Sugiyono, 2008). Dalam hal ini semua data mahasiswa S1 STIE "KBP" padang 5 tahun terakhir tahun pelaporan 2016 ganjil berjumlah 1030 orang, manajemen S1 tahun 2016 ganjil berjumlah 625 orang dan akuntansi berjumlah 405 orang.

2. Sampel

Sampel adalah bagian dari populasi yang diambil untuk diteliti. Metode pengambilan sample dilakukan dengan cara Accidental sampling yaitu bentuk pengambilan sample berdasarkan kebetulan dimana, siapa saja yang kebetulan bertemu dengan peneliti dan dianggap cocok menjadi sumber data yang akan menjadi sample peneliti ini (Sugiyono, 2001).

\section{HASIL DAN PEMBAHASAN}

Uji Validitas Harga

Tabel 4.3

\section{Hasil Uji Validitas Variabel Harga}

\begin{tabular}{|l|r|c|}
\hline & $\begin{array}{c}\text { Corrected Item- } \\
\text { Total Correlation }\end{array}$ & Keterangan \\
\hline P1 & .540 & Valid \\
P2 & .536 & valid \\
P3 & .572 & Valid \\
P4 & .576 & Valid \\
P5 & .573 & Valid \\
P6 & .631 & Valid \\
P7 & .653 & valid \\
P8 & .579 & Valid \\
P9 & .664 & Valid \\
P10 & .562 & valid \\
\hline
\end{tabular}

Sumber : SPSS 16 
Periklanan Melalui Internet

Tabel 4.4

Hasil Uji Validitas Variabel Iklan

\begin{tabular}{|l|r|c|}
\hline & $\begin{array}{r}\text { Corrected Item-Total } \\
\text { Correlation }\end{array}$ & Keterangan \\
\hline P1 & .721 & Valid \\
P2 & .571 & valid \\
P3 & .635 & Valid \\
P4 & .584 & Valid \\
P5 & .581 & Valid \\
P6 & .554 & Valid \\
P7 & .494 & valid \\
P8 & .603 & Valid \\
P9 & .584 & Valid \\
P10 & .539 & valid \\
\hline
\end{tabular}

Sumber : SPSS 16

Keputusan Pembelian

Tabel 4.5

Hasil Uji Validitas Variabel Keputusan

Pembelian

\begin{tabular}{|l|r|c|}
\hline & $\begin{array}{r}\text { Corrected Item- } \\
\text { Total Corre lation }\end{array}$ & keterangan \\
\hline P1 & .601 & Valid \\
P2 & .410 & valid \\
P3 & .580 & Valid \\
P4 & .552 & Valid \\
P5 & .627 & Valid \\
P6 & .574 & Valid \\
P7 & .561 & valid \\
\hline
\end{tabular}

Sumber : SPSS 16
Uji Realibilitas

Tabel 4.6

Hasil Uji Reliabilitas

\begin{tabular}{|c|l|c|c|}
\hline No & Variabel & $\begin{array}{c}\text { Cronbach's } \\
\text { Alpha }\end{array}$ & Keterangan \\
\hline $\mathbf{1}$ & Harga & 0,870 & Reliabel \\
\hline $\mathbf{2}$ & Iklan & 0,869 & Reliabel \\
\hline $\mathbf{3}$ & $\begin{array}{l}\text { Keputusan } \\
\text { Pembelian }\end{array}$ & 0,814 & Reliabel \\
\hline
\end{tabular}

Sumber : Data primer yang diolah, 2017

Dari tabel 4.6 dapat diambil kesimpulan bahwa dari uji reliabilitas dihasilkan nilai Cronbach's Alpha untuk variabel penelitian Harga, Iklan, dan Keputusan Pembelian lebih besar dari 0,600 yang memberikan hasil bahwa variabel yang diteliti memenuhi syarat untuk konsistensi. Jadi item-item pertanyaan untuk variabel tersebut dapat dipakai sebagai alat ukur dalam penelitian.

Tabel 4.11

Hasil Uji Regresi Linear Berganda

\begin{tabular}{|l|r|r|r|}
\hline \multirow{2}{*}{ Model } & \multicolumn{2}{|c|}{$\begin{array}{c}\text { Unstandardized } \\
\text { Coefficients }\end{array}$} & $\begin{array}{c}\text { Standardized } \\
\text { Coefficients }\end{array}$ \\
\cline { 2 - 4 } & \multicolumn{1}{|c|}{$\mathrm{B}$} & Std. Error & \multicolumn{2}{c|}{ Beta } \\
\hline 1 (Constant) & .980 & .751 & \\
$\mathrm{X} 1$ & .583 & .077 & .837 \\
$\mathrm{X} 2$ & .099 & .080 & .136 \\
\hline
\end{tabular}

Sumber : SPSS 16

Bentuk persamaan regresi dapat di tulis sebagai berikut :

$\mathrm{Y}=0,980+0,583 \mathrm{X} 1+0,099 \mathrm{X} 2$ 
Hasil persamaan regresi berganda tersebut di atas memberikan pengertian bahwa :

1. Nilai constant sebesar 0,980 artinya jika variabel yang di teliti, dalam hal ini Harga dan Iklan nilainya nol, maka Keputusan pembelian tetap bernilai 0,980 .

2. Nilai koefisien regresi Harga terhadap Keputusan pembelian 0,583 yang berarti apabila Harga bertambah sebesar satu satuan, maka akan meningkatkan keputusan pembelian sebesar 0,583 .

3. Nilai koefisien regresi iklan terhadap keputusan pembelian 0,099 yang berarti apabila iklan bertambah sebesar satu satuan, maka akan meningkatkan keputusan pembelian sebesar 0.099.

\section{Kolerasi dan Determinasi}

Tabel 4.12

Uji Koefisien Determinasi ( $\mathbf{R}^{\mathbf{2}}$ )

Model Summary

\begin{tabular}{|l|r|r|r|r|}
\hline Model & \multicolumn{1}{|c|}{$\mathrm{R}$} & R Square & $\begin{array}{c}\text { Adjusted R } \\
\text { Square }\end{array}$ & $\begin{array}{c}\text { Std. Error } \\
\text { of the } \\
\text { Estimate }\end{array}$ \\
\hline 1 & $.969^{\mathrm{a}}$ & .939 & .938 & .974 \\
\hline
\end{tabular}

Sumber : SPSS 16

Pada tabel di atas di peroleh nilai adjusted $\mathrm{R}$ square adalah 0,938 artinya sebesar 93,8\% variabel Harga dan Iklan mampu menjelaskan terhadap Keputusan pembelian dan sisanya $6,2 \%$ dipengaruhi oleh faktor lain yang tidak diteliti.

\section{Hipotesis}

\section{Hasil Uji F}

Tabel 4.13

Uji F ( Simultan )

ANOVA $^{b}$

\begin{tabular}{|l|r|r|r|r|r|}
\hline Model & \multicolumn{1}{|c|}{$\begin{array}{c}\text { Sum of } \\
\text { Squares }\end{array}$} & df & $\begin{array}{r}\text { Mean } \\
\text { Square }\end{array}$ & F & Sig. \\
\hline 1 Regression & 1284.125 & 2 & 642.062 & 677.363 & $.000^{2}$ \\
Residual & 83.414 & 88 & .948 & & \\
Total & 1367.538 & 90 & & & \\
\hline
\end{tabular}

Sumber : SPSS 16

Nilai F hitung sebesar 677.363 yang signifikan $0.000^{\mathrm{a}}$. Karena sig $<0,05$ ini berarti rumusan hipotesis yang menyatakan bahwa harga dan iklan berpengaruh secara simultan terhadap. Maka Ho ditolak dan H1 diterima.

Uji T

Tabel 4.14

Uji T ( Parsial )

\begin{tabular}{|rl|r|r|}
\hline \multicolumn{2}{|l|}{ Model } & \multicolumn{1}{c|}{$\mathrm{T}$} & \multicolumn{1}{c|}{ Sig } \\
\hline 1 & (Constant) & 1.684 & .096 \\
& $\mathrm{X} 1$ & 36.681 & .000 \\
\hline 1 & (Constant) & .849 & .398 \\
\cline { 2 - 4 } & $\mathrm{X} 2$ & 28.175 & .000 \\
\hline
\end{tabular}

Sumber : Data Primer yang diolah, 2017

Hasil pengujian hipotesis secara parsial dapat dilihat pada tabel 4.14 dapat 
disimpulkan uji parsial variabel harga terhadap variabel keputusan pembelian dari hasil pengujian yang dilakukan dan nampak pada Tabel 4.14 diperoleh nilai t hitung sebesar 36,681 dengan nilai signifikannya sebesar $0.000<\alpha=0.05$ (level of signifikan). Maka Ho diterima sehingga H1 ditolak, hal ini menunjukan adanya pengaruh positif dan signifikan variabel harga terhadap variabel keputusan pembelian.

Selanjutnya uji parsial variabel Iklan terhadap variabel keputusan pembelian dari hasil pengujian yang dilakukan dan nampak pada Tabel 4.14 diperoleh nilai $\mathrm{t}$ hitung sebesar 28,175 dengan nilai signifikannya sebesar 0.000 $<\alpha=0.05$ (level of signifikan). Maka Ho diterima sehingga H1 ditolak, hal ini menunjukan adanya pengaruh positif dan signifikan variabel iklan terhadap variabel keputusan pembelian.

\section{Kesimpulan}

1. Pengaruh variabel harga terhadap variabel keputusan pembelian dari hasil pengujian diperoleh nilai $\mathrm{t}$ hitung sebesar 36,681 dengan nilai signifikannya sebesar $0.005<\alpha=$ 0.05 (level of signifikan). Hal ini menunjukan adanya pengaruh positif dan signifikan variabel harga terhadap variabel keputusan pembelian. Hal ini mengidentifikasikan bahwa semakin baik strategi harga yang di tawarkan oleh perusahaan akan membuat semakin senang, sehingga mereka akan membeli produk tersebut.

2. Pengaruh Iklan terhadap variabel keputusan pembelian dari hasil pengujian yang dilakukan diperoleh nilai $\mathrm{t}$ hitung sebesar 28,175 dengan nilai signifikannya sebesar $0.005<\alpha$ $=0.05$ (level of signifikan. Hal ini menunjukan adanya pengaruh positif dan signifikan variabel iklan terhadap variabel keputusan pembelian. Fungsi iklan di sini hanya sebagai pembuktian produk saja. Sebab pengaruh yang dihasilkan oleh iklan tidak terlalu besar secara langsung melalui televisi maupun media cetak. Konsumen saat ini lebih bersifat cerdas dalam memilih produk yang mereka gunakan. Mereka tidak hanya menggunakan produk berdasarkan iklan televisi maupun media cetak saja tetapi juga berdasarkan pengalaman dan informasi di internet mengenai produk.

\section{Saran}

Berdasarkan hasil penelitian yang telah dilakukan, penulis mempunyai beberapa saran, yaitu :

1. Diharapkan kepada peneliti selanjutnya untuk dapat menggunakan penelitian ini sebagai referensi yang nantinya akan memberikan perbandingan dalam 
2. melakukan penelitian pada bidang yang sama dimasa yang akan datang.

3. Bagi peneliti agar dapat mengkaji lebih dalam wawasan dan pendalaman pengetahuan dalam manajemen pemasaran yang berkaitan dengan Pengaruh harga dan periklanan melalui internet terhadap keputusan pembelian produk sabun merek LUX pada Mahasiswa STIE “KBP” Padang.

4. Diharapkan penelitian ini dapat menjadi referensi untuk mengambil suatu keputusan pada terutama yang berkaitan dengan Pengaruh harga dan

\section{DAFTAR PUSTAKA}

Ahyari, A. 2010. Dasar-dasar Manajemen. Edisi I. Jilid Dua. Yogyakarta. UGM. Penerbit BPFE.

Hidayati, R. R., \& Marlius, D. (2018). Aktivitas Promosi Dalam Meningkatkan Dana Pihak Ketiga Pada PT. Bank Perkreditan Rakyat (BPR) Batang Kapas Pesisir Selatan. https://doi.org/10.31227/osf.io/8d gqn

Kotler, P. 2010. Manajemen Pemasaran : Analisis, Perencanaan, Implementasi, dan Kontrol. Jilid 1. Edisi Bahasa Indonesia dari Principles of Marketing 9e. Penerbit PT. Prenhalindo. Jakarta.

Kotler, P dan G. Amstrong. 2008. Manajemen Pemasaran. Edisi ketiga belas. Jilid dua. Erlangga. Jakarta. periklanan melalui internet terhadap keputusan pembelian produk sabun merek LUX pada Mahasiswa STIE “KBP” Padang.

Bagi penelitian selanjutnya penulis juga memberikan saran untuk memperluas wilayah atau lokasi penelitian mengingat keterbatasan penelitian hanya meneliti pada satu tempat Mahasiswa STIE "KBP" Padang dan penelitian mendatang hendaknya mengembangkan model penelitian dengan menambahkan variabel - variabel lainnya.

Kotler, P. 2011. Manajemen Pemasaran di Indonesia, Edisi Pertama. Penerbit Salemba Empat. Jakarta.

Mangkunegara, P. A., 2010. Manajemen Sumber Daya Manusia. Cetakan ke-3. PT. Remaja Roskadarya. Bandung.

Maholtra, N. K, 2010. Marketing Research: An Applied Orientation. Third Edition Prentice Hall Inc. New Jersey.

Marlius, D. (2017). Keputusan Pembelian Berdasarkan Faktor Psikologis Dan Bauran Pemasaran Pada PT. Intercom Mobilindo Padang. Jurnal Pundi. Volume 1. No. 1. Hal. 5766. https://doi.org/10.31575/jp.v1i1.9

Marlius, D. (2016). Pengaruh Bauran Pemasaran Jasa Terhadap Minat Nasabah Dalam Menabung Pada Bank Nagari Cabang Muaralabuh. https://doi.org/10.31227/osf.io/vdq gx 
Pratiwi, P. A. O. A. 2010. Tentang Pengaruh Marketing Mix terhadap Keputusan Konsumen dalam Pembelian Mobil Avanza pada PT. Agung Automall Denpasar.Skripsi. Fakultas Ekonomi. Universitas Udayana. Bali.

Perwira, F.T. 2013. Pengaruh Produk, Harga dan Promosi terhadap Keputusan Pembelian Toyota Yaris pada PT. Nasmoco Gombel Semarang. Skripsi. Fakultas Ilmu Sosial dan Ilmu Politik. Universitas Diponegoro. Semarang.

Suti, I. 2010. Pengaruh kualitas Produk, Harga dan Promosi terhadap Keputusan Pembelian Handphone Esia ( Studi Kasus pada Mahasiswa UIN Syarif Hidayatullah Jakarta). Skripsi. Fakultas Ekonomi dan Bisnis. Universitas Islam Negeri Syarif Hidayatullah Jakarta.

Sinamora, H. 2010. Manajemen Sumber Daya Manusia. Edisi Ketiga. STIE YKPN. Yogyakarta.

Sugiyono, 2010.Metode Penelitian Kuantitatif, Kualitatif, dan $R \& D$. Alfabeta. Bandung.

Susanti, F. (2014). Pengaruh Tarif Iklan Terhadap Pendapatan Pada PT. Radio Swara Carano Batirai Indah Batusangkar. https://doi.org/10.31227/osf.io/dy8 $\underline{63}$

Susanti, F. (2015). Pengaruh Bauran Promosi Terhadap Keputusan Klien Dalam Memilih Radio Carano Sebagai Media Promosi Iklan. https://doi.org/10.31227/osf.io/b9w s7

Stanton, W. J. 2009.Alih Bahasa Yohannes Lamarto, Fundamental of Marketing. Erlangga. Jakarta
Tjiptono, F. 2010. Manajemen Jasa. Jakarta: Banyumedia. 